Article

\title{
Combination of Fuzzy Logic and Analytical Hierarchy Process Techniques to Assess Potassium Saturation Percentage of Some Calcareous Soils (Case Study: Fars Province, Southern Iran)
}

\author{
Marzieh Mokarram * and Mahdi Najafi-Ghiri \\ Department of Range and Watershed Management, College of Agriculture and Natural Resources of Darab, \\ Shiraz University, Shiraz 71946-85115, Iran; mnajafighiri@yahoo.com \\ * Correspondence: m.mokarram@shirazu.ac.ir; Tel.: +98-917-802-0115 \\ Academic Editor: Ritaban Dutta
}

Received: 28 August 2016; Accepted: 28 October 2016; Published: 6 December 2016

\begin{abstract}
This research was carried out to evaluate the capability of a combined fuzzy logic-based approach and analytical hierarchy process (AHP) for potassium saturation percentage (KSP) estimation in some calcareous soils of southern Iran. Based on a reconnaissance soil survey, 52 soil series were selected and different physical and chemical properties were determined. Five soil parameters including clay, cation exchange capacity, calcium carbonate equivalent, electrical conductivity, and organic carbon were chosen for analysis. Mapping was developed with the kriging method for each parameter. Different fuzzy membership functions were employed and weights for all parameters were calculated according to AHP. Finally, KSP classes were provided for each land unit. Results indicated that about $60 \%$ of the studied area is classified as having moderate to high KSP content $(>3 \%)$ and $40 \%$ of had low or very low KSP content $(<3 \%)$. Then 15 sample points were used for determination of the accuracy of the fuzzy method. Results showed that the fuzzy and AHP methods have a high accuracy for KSP estimation in the studied soils. Further development of the fuzzy and AHP methods would be worthwhile for improving the accuracy of KSP analysis.
\end{abstract}

Keywords: potassium saturation percentage (KSP); calcareous soils; GIS; fuzzy; analytical hierarchy process (AHP)

\section{Introduction}

Potassium is an essential element for plants and its importance in agriculture is well known. Potassium saturation percentage (KSP) is an index of K fertility of soil and is also another index for assessment of $\mathrm{K}$ status and $\mathrm{K}$ buffering capacity in some countries [1,2]. It is defined as exchangeable $\mathrm{K}$ divided by cation exchange capacity (CEC), expressed as a percentage. In fact, KSP indicates the ability of soil to adsorb and buffer K ions and is directly related to CEC. Low KSP indicates that K ions occupy a small portion of CEC [3]. Pagel and Insa (1974) proposed the critical value for KSP as being 2.3\% [4]. However, some soil physical and chemical properties, climate (temperature regimes), soil development, mineralogy, and soil depth may also affect its content [1].

Nowadays, some analytical methods such as fuzzy logic-based approach and analytical hierarchy process (AHP) as an expert-based system are used for analysis and mapping of soil properties. The AHP technique has the ability to incorporate different types of data and compare two parameters at the same time by using the pair-wise comparison method [5]. Although the fuzzy and AHP methods have been used for different purposes such as agricultural best management practices, contaminated land management, watershed management, etc. by many researchers [6-8], no information is available 
about the use of these techniques for the mapping of essential soil elements for plant growth such as $\mathrm{N}, \mathrm{P}$ and $\mathrm{K}$.

Many fuzzy membership functions have been developed for different soils [9]. These methods are implemented in Geography Information System (GIS) and analyses are performed for each raster cell to produce the soil maps. Input attributes are classified into different classes (high, medium, low, and very low values). However, for determination of fuzzy maps for each criterion, the main problem is the determination of the relative weight of these criteria and overlaying these maps to obtain the final map. The analytical hierarchy process (AHP) is known to be a good method to overcome this problem [5-10].

The current research was carried out to study the content of KSP and its variation in 52 calcareous soils of southern Iran and to map KSP as an index of K fertility using the fuzzy and AHP methods. The results of this investigation may be important for $\mathrm{K}$ fertility management of calcareous soils of southern Iran.

\section{Materials and Methods}

\subsection{Study Area and Data Set}

The study area is located in Fars province, southern Iran, between latitudes $27^{\circ} 03^{\prime} \mathrm{N}-31^{\circ} 40^{\prime} \mathrm{N}$ and longitudes $48^{\circ} 56^{\prime} \mathrm{E}-50^{\circ} 36^{\prime} \mathrm{E}$ with an area of $12,442 \mathrm{~km}^{2}$ (Figure 1). There are three distinct climatic regimes in the study area. These include the mountainous area of the north and northwest with moderate cold winters and mild summers, the central regions with relatively rainy mild winters and hot dry summers, and the south and southeast region with cold winters and hot summers. The highest and lowest elevations of the studied region are 3915 and $115 \mathrm{~m}$ above sea level, respectively.

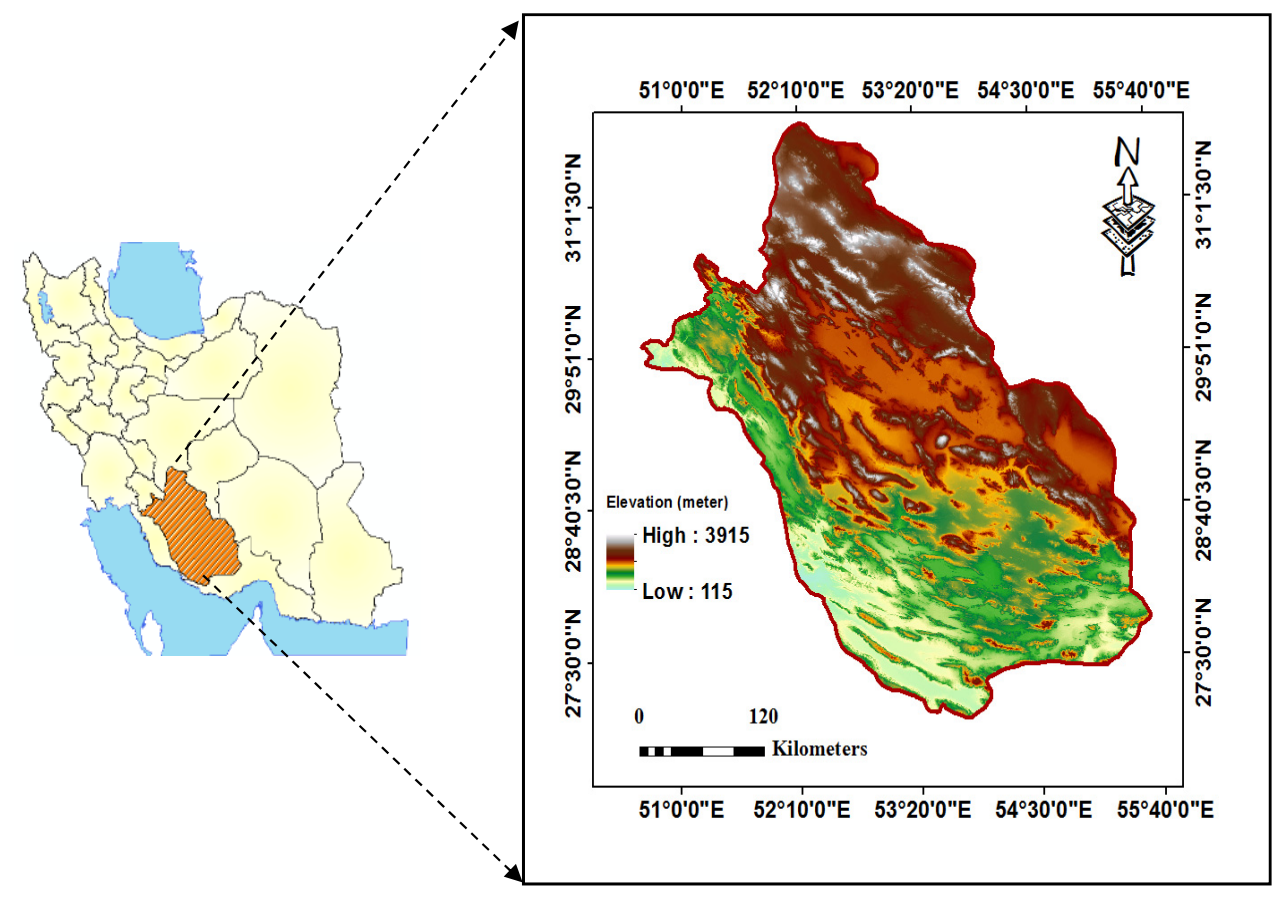

Figure 1. Location of the study area in southern Iran.

Based on a reconnaissance soil survey, 52 soil series in the different climatic regions were selected (Figure 2), and 0-20 cm horizons were sampled, air-dried, and sieved $(<2 \mathrm{~mm})$ for laboratory analyses in February 2014. Particle size distribution including sand, silt, and clay percentages was determined after dissolution of $\mathrm{CaCO}_{3}$ with $2 \mathrm{~N} \mathrm{HCl}$, decomposition of organic matter with $30 \% \mathrm{H}_{2} \mathrm{O}_{2}$ and removal of salts with repeated washing. The soils were dispersed using sodium hexametahposphate, and 
the sand $(50-2000 \mu \mathrm{m})$, silt $(2-50 \mu \mathrm{m})$, and clay $(<2 \mu \mathrm{m})$ fractions were separated by sedimentation and determined by the pipette method [11]. Calcium carbonate equivalent was determined by acid neutralization (CCE) [12]. Organic carbon was determined by wet oxidation with chromic acid and back titrated with ferrous ammonium sulphate [13]. Electrical conductivity was determined in the saturated extract [12]. Cation exchange capacity (CEC) was determined using sodium acetate at a $\mathrm{pH}$ of 8.2 [14]. Exchangeable $\mathrm{K}$ was extracted with four times extractions of $5 \mathrm{~g}$ soil with $25 \mathrm{~mL}$ of $1.0 \mathrm{M}$ $\mathrm{NH}_{4} \mathrm{OAc}(\mathrm{pH} 7.0)$ after 10 min shaking [15]. The mentioned attributes were used to determine the KSP classes.

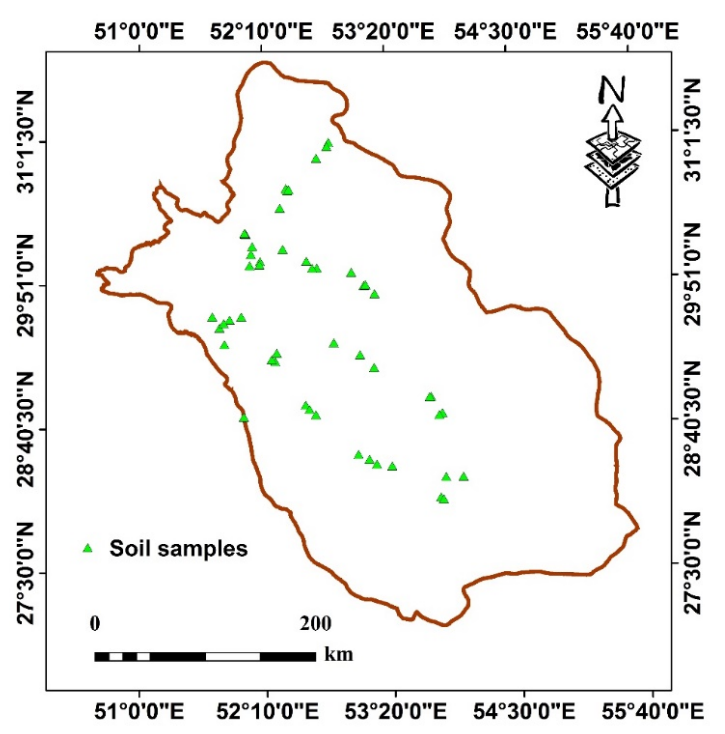

Figure 2. The location of 52 soil samples in the study area.

\subsection{Methods}

\subsubsection{Kriging Interpolation}

The geostatistics method was used for producing interpolation maps of the soil attributes. The prediction of the soil attributes was carried out by using a kriging method in the study area [16]. The presence of a spatial structure where observations close to each other are more alike than those that are far apart (spatial autocorrelation) is a prerequisite to the application of geostatistics. The experimental variogram measures the average degree of dissimilarity between predicted values and a nearby data value and thus can depict autocorrelation at various distances. The value of the experimental variogram for a separation distance $h$ (referred to as the lag) is half the average squared difference between the values $z\left(x_{i}\right)$ and $z\left(x_{i}+h\right)$ [16]:

$$
\bar{\gamma}(h)=\frac{1}{2 n(h)} \sum_{i=1}^{n}\left[z\left(x_{i}\right)-z\left(x_{i}+h\right)\right]^{2}
$$

where $n$ is the number of pairs of data point, which are separated by the distance $h$, and $Z\left(x_{i}\right)$ and $Z\left(x_{i}+h\right)$ are the observed values of the variable at the locations $x_{i}$ and $x_{i}+h$, respectively. From analysis of the experimental variogram, a suitable model is then fitted, usually by weighted least squares and the four parameters (sill, range, nugget variance, and anisotropy) are determined. The sill refers to variance value at which the curve reaches the plateau. The total separation distance from the lowest variance to the sill is known as the range. The variance at separation distance of zero is called the nugget variance. Variogram modeling is a key step between spatial description and spatial prediction. The main application of kriging is the prediction of attribute values at unsampled locations. 


\subsubsection{Fuzzy Classification}

Mathematically, a fuzzy set can be defined as follows [17]:

$$
\mathrm{A}=\left\{\mathrm{x}, \mu_{\mathrm{A}}(\mathrm{x})\right\} \text { foreach, } \mathrm{x} \in \mathrm{X}
$$

where $X$ is a collection of objects denoted generically by $x$. The $\mu_{\mathrm{A}}$ is the membership function (MF) that defines the grade of membership of $x$ in a fuzzy set. The MF takes values between and including 1 and 0 for all $\mathrm{A}$ where $\mu_{\mathrm{A}}=0$ means that the value of $x$ does not belong to $\mathrm{A}$ and $\mu_{\mathrm{A}}=1$ means that it belongs completely to A. Alternatively $0<\mu_{\mathrm{A}}(x)<1$ implies that $x$ belongs in a certain degree to $\mathrm{A}$. If $X=\left\{x_{1}, x_{2}, \ldots x_{n}\right\}$, the previous equation can be written as following [17]:

$$
A=\left\{\left[x_{1}, \mu_{A}\left(x_{1}\right)\right]+\left[x_{2}, \mu_{A}\left(x_{2}\right)\right]+\ldots \ldots+\left[x_{n}, \mu_{A}\left(x_{n}\right)\right]\right\}
$$

In simple terms, Equations (2) and (3) mean that for every $x$ that belongs to the set $\mathrm{X}$, there is a MF that describes the degree of ownership of $x$ in A.

The following MF was used for CCE and electrical conductivity (EC) [18-20].

$$
\mu_{A}(X)=f(x)= \begin{cases}0 & x \leq a \\ x-a / b-a & a<x<b \\ 1 & x \geq b\end{cases}
$$

where $x$ is the input data and $a, b$ are the limit values.

For CEC, OM, and clay, the following MF was used [18-20].

$$
\mu_{A}(X)=f(x)= \begin{cases}1 & x \leq a \\ b-x / b-a & a<x<b \\ 0 & x \geq b\end{cases}
$$

where $x$ is the input data and $a, b$ are the limit values.

\subsubsection{The Analytical Hierarchy Process Method}

The analytical hierarchy process (AHP) is based on a pair wise comparison matrix. It is calculated using Equations (6) and (7):

$$
\begin{gathered}
a_{i j}=a_{i k} \cdot a_{k j} \\
a_{i j}=1 / a_{j i}
\end{gathered}
$$

where $i, j$, and $k$ are any decision criteria of the matrix.

\subsubsection{Combination of Fuzzy and AHP methods}

In order to prepare the KSP map, it is necessary to combine the raster values containing the different fuzzy parameters. $A_{1}, \ldots A_{\mathrm{k}}$. So for this purpose, the weights $\mathrm{W} 1$ and $\mathrm{Wk}$ were calculated using AHP in ArcGIS [21].

Equations (8) and (9) present the convex combination:

$$
\begin{gathered}
\mu_{A}=\sum_{j=1}^{k} w_{j} \cdot \mu_{A(x)}, x \in X \\
\sum_{j=1}^{k} w_{j}=1, w_{j}>0
\end{gathered}
$$


First, model parameters maps were constructed by interpolation between the 52 sampling points using the kriging method. Next fuzzy logic was applied to create a fuzzy parameter map for each parameter. To arrive at an integrated evaluation of the KSP classes, the fuzzy parameter maps were aggregated into a suitability map following a weighted summation, using the AHP.

\section{Results and Discussion}

Some physical and chemical properties of the soil samples are shown in Table 1. All soils were calcareous and the average calcium carbonate content was $41 \%$. A wide range of clay content, salinity, CEC, and organic matter contents was observed in the studied soils. This may be due to the different parent materials (including calcareous, gypsiferous, and saline alluviums), different climatic zones, different physiographic positions (including lowland, piedmont plain, river terrace, alluvial fan, and alluvial plain), different land covers (forest, range, agriculture, etc.), and divergent mineralogical compositions. Higher values of CCE were found in southern and to some extent southwestern locations within the studied area; while the lower values were related to the northwest part. Cation exchange capacity of the south and center parts were considerably lower than the north part. Clay content showed no regular distribution, but some small-scale regions in the center to the north part had soils with higher than $40 \%$ clay content. Generally, soil salinity was a serious problem for some parts in the west of the studied region. Most parts in the studied region had lower than $1 \%$ organic matter (OM) in the surface soils, however, some parts in southern Fars had a considerable content of OM (higher than $5 \%)$. Generally, soils that developed in cooler and more humid regions had higher clay, organic matter, and CEC and lower CCE, EC, and pH [22]. Significant correlations were found between CEC and CCE $(-0.67, p<0.01), \mathrm{OM}(0.90, p<0.01)$, sand $(-0.44, p<0.01)$, and clay $(0.44, p<0.01)$. Clay content was also correlated with CCE $(-0.32, p<0.01)$, sand $(-0.68, p<0.01)$, and silt $(-0.42, p<0.01)$. Significant relationships of the mentioned parameters with different forms of K and KSP in calcareous soils of Iran have been previously reported by Najafi-Ghiri et al. [1] and Nabiollahy et al. [23]. The value of KSP in the studied soils ranged from $0.4 \%$ to $9.2 \%$ with an average of $4.4 \%$. These results are comparable with the findings of Al-Zubaidi [24] for Iraqi soils (mean of 4.51\%) and higher than the findings of Al-Zubaidi et al. [3] for some Lebanese soils (mean of 1.73\%).

Table 1. Variation of the content of KSP as conditioning factors in the study area.

\begin{tabular}{cccccccc}
\hline Soil Properties & Clay \% & Sand \% & Silt \% & CCE \% & CEC Cmol(+) $\mathbf{k g}^{-\mathbf{1}}$ & EC dSm $^{-1}$ & OM \% \\
\hline Maximum & 53 & 81 & 89 & 69 & 56 & 57.1 & 21.0 \\
Minimum & 1 & 1 & 12 & 3 & 5 & 0.2 & 0.1 \\
Average & 25 & 27 & 48 & 41 & 15 & 4.2 & 3.1 \\
SD & 13.57 & 17.31 & 12.24 & 16.65 & 9.00 & 10.19 & 3.02 \\
\hline
\end{tabular}

KSP: potassium saturation percentage; SD: standard deviation; CCE: calcium carbonate equivalent; CEC: cation exchange capacity; EC: electrical conductivity; OM: organic matter.

In this study, the spline, inverse distance weighted (IDW), and simple kriging methods (Gaussian, circular, spherical, and exponential models) were used for production of raster maps for each soil parameter in ArcGIS 10.2 software (Esri, New York, NY, USA). These methods are usual for the preparation of interpolation maps. For selection of the best method we used root-mean-square deviation (RMSE); $70 \%$ of the data was used as training data (37 samples), and $30 \%$ was used for testing data (15 samples), with the data randomly allocated for either training or testing purposes. The results of RMSE for three models showed that the simple kriging method (circular model) with the lowest RMSE is the best model for prediction of soil parameters (Table 2).

Therefore, the prediction of soil properties was carried out by using the circular model in the study area. The maps of soil parameters were constructed by kriging method interpolation among 52 sampling points which are shown in Figure 3. 
Table 2. Root mean square errors for each parameters by inverse distance weighted (IDW) and kriging methods.

\begin{tabular}{ccccccc}
\hline \multirow{2}{*}{ Factor } & \multicolumn{3}{c}{ Kriging } & \multirow{2}{*}{ IDW } & Spline \\
\cline { 2 - 5 } & Gaussian & Circular & Spherical & Exponential & & \\
\hline Clay, \% & 1.28 & 1.10 & 1.21 & 1.31 & 1.11 & 1.12 \\
Sand, \% & 3.20 & 3.17 & 3.71 & 3.21 & 4.10 & 4.20 \\
Silt, \% & 3.10 & 2.98 & 3.40 & 3.53 & 3.21 & 3.10 \\
CCE, \% & 3.33 & 3.24 & 3.41 & 3.54 & 3.28 & 3.81 \\
CEC, Cmol(+)kg $^{-1}$ & 4.10 & 3.56 & 3.81 & 4.10 & 5.20 & 4.90 \\
CC, dSm $^{-1}$ & 3.30 & 2.94 & 3.10 & 3.20 & 2.98 & 3.00 \\
OM, \% & 1.36 & 1.04 & 1.28 & 1.31 & 1.25 & 1.91 \\
\hline
\end{tabular}
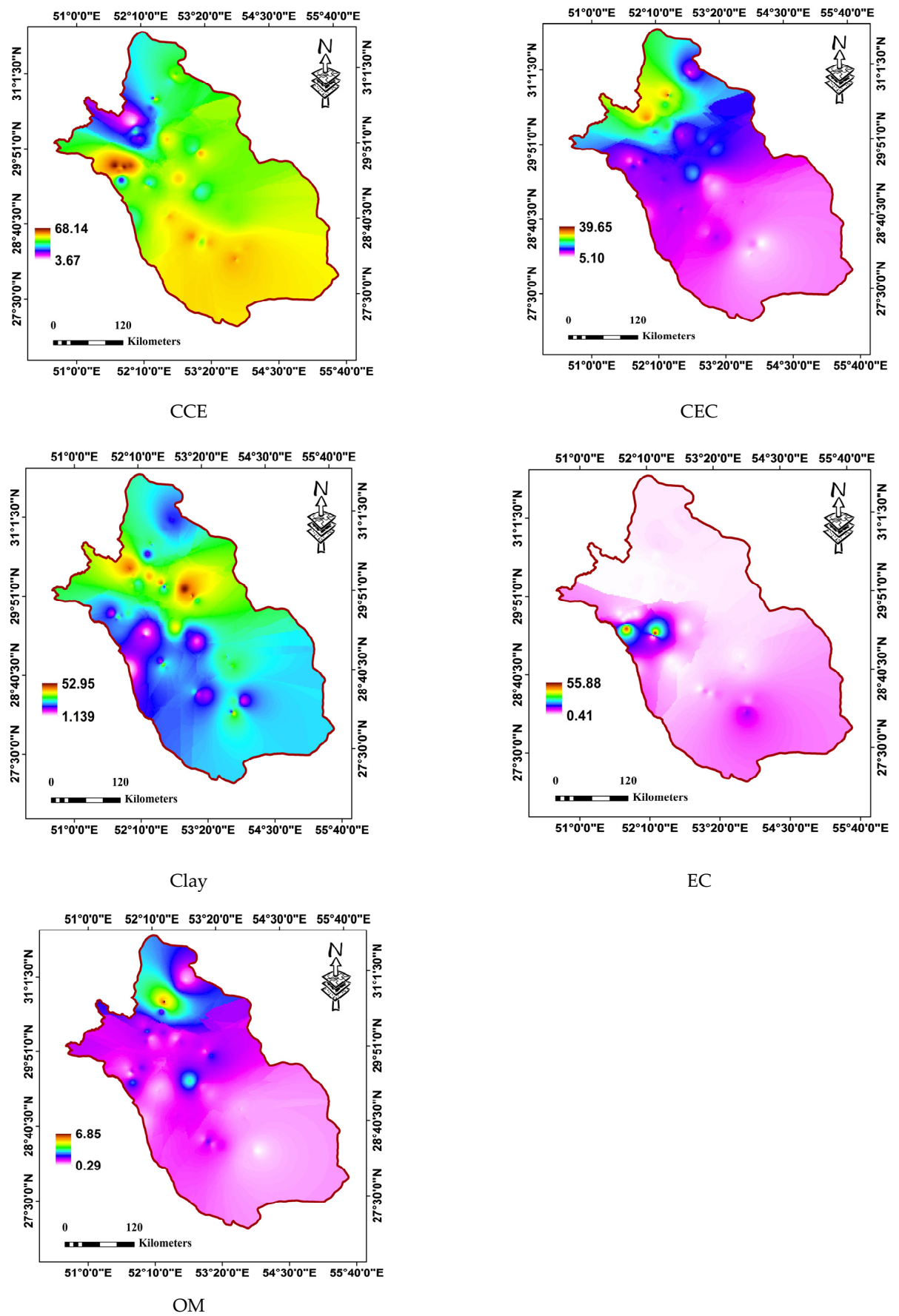

Figure 3. Interpolation maps of soil parameters by kriging method (circular model). 
Next, the capability of linear functions to calculate the fuzzy memberships was examined for prediction of the different KSP conditioning factors in ArcGIS 10.2 (extension of spatial data modeller (SDM)). In order to define membership functions, data in Table 3 was used [25-29]. According to Table 3, variations in the different KSP conditioning factors are linear. Therefore, a linear function was used to define the membership function for each parameter in this study.

Table 3. Classification of the different KSP conditioning factors.

\begin{tabular}{|c|c|c|c|c|}
\hline Factor & Low & Moderate & High & Very High \\
\hline Clay, \% & $<18$ & $18-35$ & $35-60$ & $>60$ \\
\hline CCE, \% & $<2$ & $2-15$ & $15-40$ & $>40$ \\
\hline $\mathrm{CEC}, \mathrm{Cmol}(+) \mathrm{kg}^{-1}$ & $<8$ & $8-16$ & $16-32$ & $>32$ \\
\hline $\mathrm{EC}, \mathrm{dSm}^{-1}$ & $<4$ & $4-8$ & $8-16$ & $>16$ \\
\hline OM, \% & $<1$ & $1-5$ & $5-10$ & $>10$ \\
\hline
\end{tabular}

The best fuzzy membership was achieved by using the linear functions (Equations (4) and (5)). The resulting maps for each of the KSP conditioning factors are shown in Figure 4. According to Figure 4, the CEC and OM contents in the soils of the north regions were the lowest, while CCE and clay contents in some of the soils from parts of the northeast and northwest regions were the lowest, respectively. For EC, the highest content was related to some of the soils from the west regions. Then, for overlaying the maps and preparing the KSP map, the AHP method was applied on the fuzzy maps. The pair-wise comparisons matrix that was used for preparation of the weights for each KSP conditioning factor was determined by consulting experts opinions including soil investigators (six experts) about the chemistry of soil K, agronomists (six experts) about K absorption and utilization by plant roots, geomorphologists (three experts) about the relationships between different soil properties and land physiography with soil $\mathrm{K}$, and soil mineralogists (three experts) about the importance of different clay minerals in $\mathrm{K}$ release, fixation, and availability; these weights are indicated in Table 4. By taking each of the column values and dividing by the sum of the column the average weight was calculated for each of the parameters. According to expert opinions and a previous report from Najafi-Ghiri et al. [1], it was determined that CEC, clay, CCE, OM, and EC were the most important parameters that had the highest effects on KSP, and the best relationship was observed between CEC and KSP. While KSP was defined as a percentage of CEC that was determined by $\mathrm{K}$, with an increase in CEC, the value of KSP decreased. On the other hand, CEC is related to clay and organic matter content and thus these parameters may affect the KSP value [25].
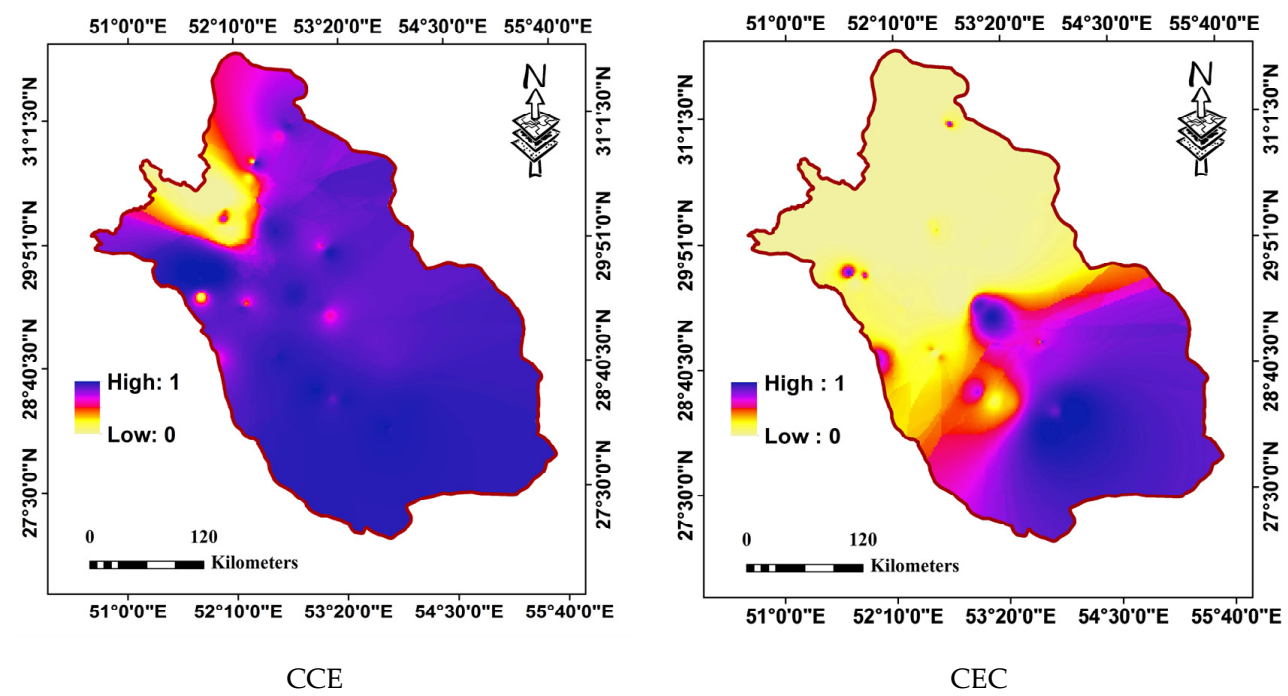

Figure 4. Cont. 


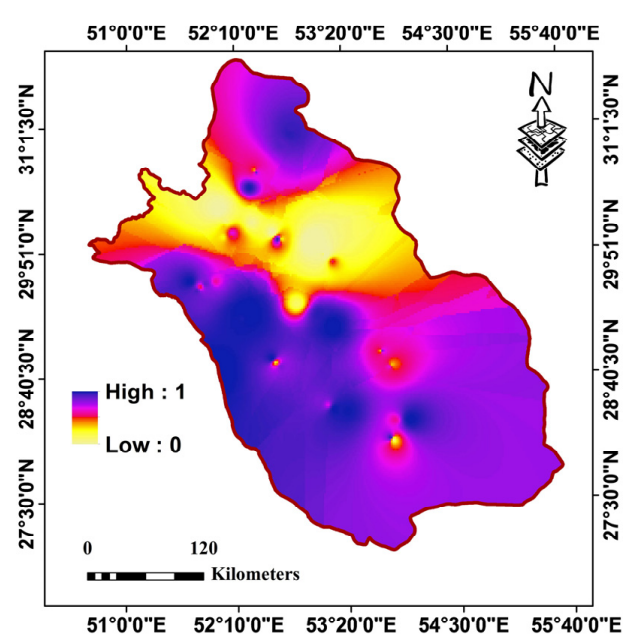

Clay

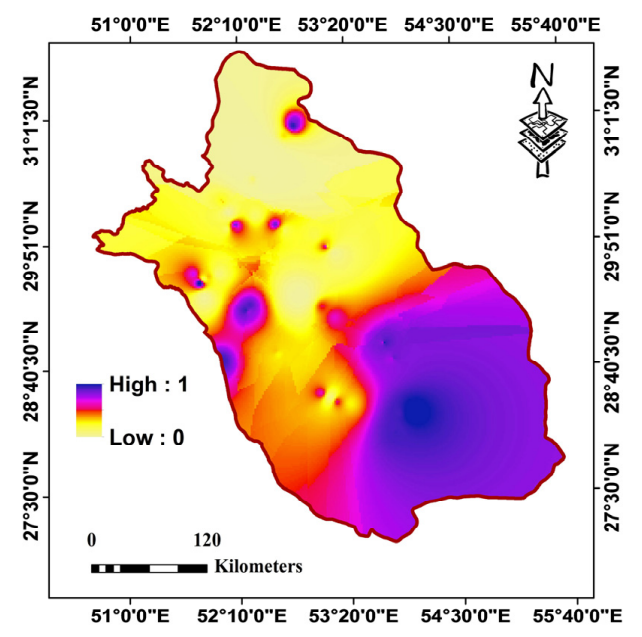

$\mathrm{OM}$

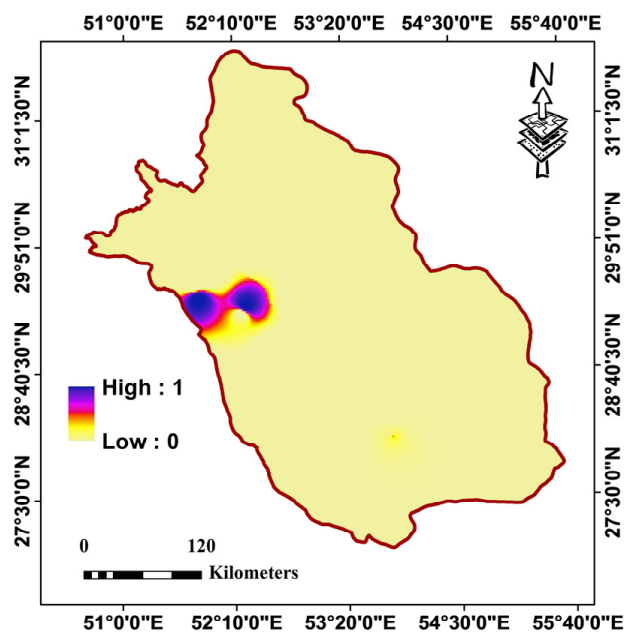

EC

Figure 4. The fuzzy maps of each parameter for estimation of KSP.

Table 4. Pair-wise comparison matrix for KSP.

\begin{tabular}{ccccccc}
\hline Factors & CEC & Clay & CCE & OM & EC & Weight \\
\hline CEC & 1 & 2 & 3 & 4 & 5 & 0.42 \\
Clay & $1 / 2$ & 1 & 2 & 3 & 4 & 0.26 \\
CCE & $1 / 3$ & $1 / 2$ & 1 & 2 & 3 & 0.16 \\
OM & $1 / 4$ & $1 / 3$ & $1 / 2$ & 1 & 2 & 0.10 \\
EC & $1 / 5$ & $1 / 4$ & $1 / 3$ & $1 / 2$ & 1 & 0.06 \\
\hline
\end{tabular}

The results of fuzzy and AHP methods are shown in Figure 5. The area of the land in each class is also shown in Table 5. Generally, the fuzzy method classifies the studied region into four classes including very low, low, moderate, and high [19]. About $60 \%$ of the studied area is classified as belonging to the moderate and high KSP classes and $40 \%$ of the studied area had low or very low KSP values. Generally, the KSP content in soils of the northwest to center area of the studied regions were the lowest, while the highest content was related to the soils of the south and southeast regions. According to Table 4, it was determined that CEC had the maximum weight (0.42) and the most negative effect on KSP value. In considering these results, it was determined that the south region of the study area, with the minimum value of $C E C$, was located in a class 4 area according to a 
KSP map (KSP values of $<1,1-3,3-5,>5$ are classes of 1, 2, 3, and 4, respectively); while the north of the study area, with the maximum value of CEC, was located in a class 1 area with the lowest KSP. As such, CEC has the most effect on the final fuzzy and AHP maps for KSP. As mentioned, CEC is related to clay content and type and organic matter content. Thus, the soils of arid land (southern Fars province) that had the lowest content of organic matter and clay with low CEC, including illite and chlorite [30], showed the highest value of KSP. On the other hand, more humid regions of Fars province (southwest area), with high organic matter content and high-charged clay like smectites, had the lowest value of KSP.

Table 5. The area of each class for KSP.

\begin{tabular}{ccc}
\hline Class & Area $\mathbf{( \% )}$ & Area $\mathbf{( k m}^{\mathbf{2}} \mathbf{)}$ \\
\hline Very low & 14.05 & 17,477 \\
Low & 28.98 & 36,067 \\
Moderate & 27.48 & 34,198 \\
High & 29.49 & 36,700 \\
Total & 100 & 124,442 \\
\hline
\end{tabular}

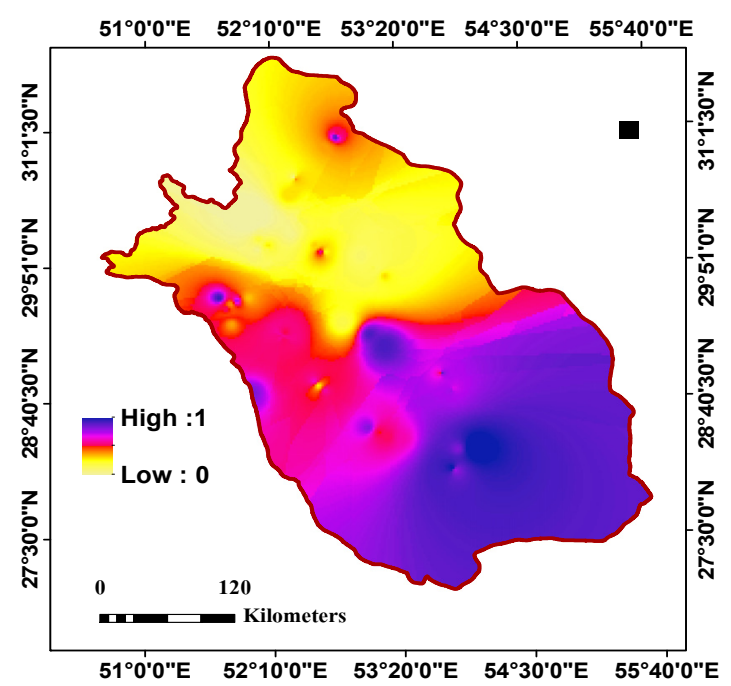

(a)

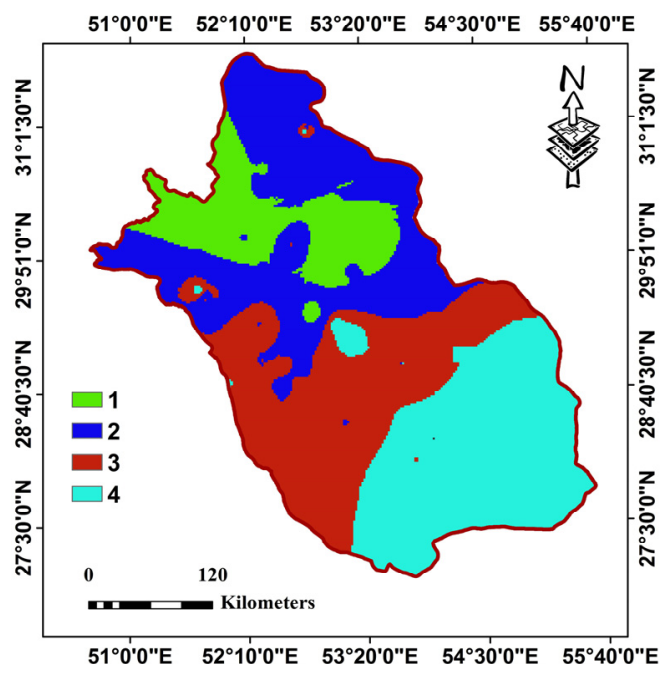

(b)

Figure 5. The KSP maps for the studied region as determined by fuzzy and analytical hierarchy process (AHP) (a) KSP map (b) reclassified map of KSP map.

For determination of the accuracy of the fuzzy method, 15 sample points (equal to $30 \%$ of the primary studied points) were used. The results are shown in Figure 6 and Table 6 . Then CCE, CEC, clay, OM, and KSP values were measured (Table 6). The comparison of the content of each parameter (test data) with KSP map (Figure 5) indicated that with decreases in the content of CEC, organic matter, and clay, the sampling point tended to be located in class 4 areas that had the highest content of KSP and vice versa. In fact, the method demonstrated high accuracy $(100 \%)$ and was shown to be useful in the prediction of KSP values. 


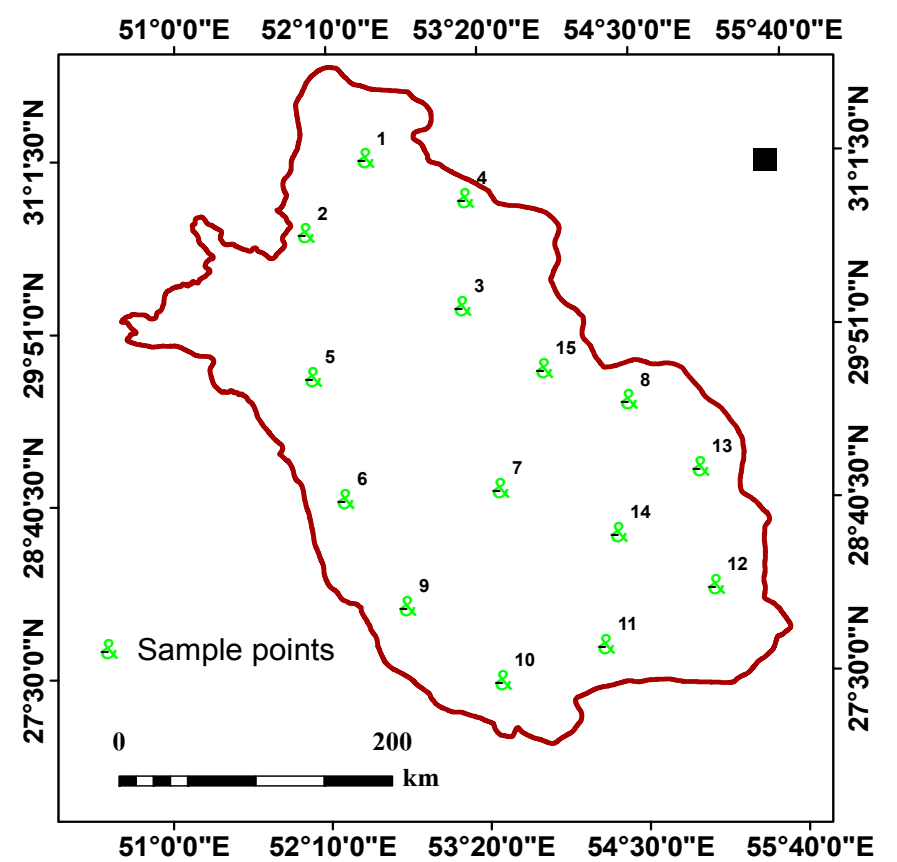

Figure 6. Position of sample points in the study area.

Table 6. Characteristics of the sample points.

\begin{tabular}{|c|c|c|c|c|c|c|c|}
\hline Sample Point & CCE, \% & CEC, $\operatorname{cmol}(+) \mathrm{kg}^{-1}$ & Clay, \% & $E C, \mathrm{dS} \mathrm{m}^{-1}$ & OM, \% & KSP, \% & Class \\
\hline 1 & 36.22 & 20.36 & 22.01 & 20.36 & 2.39 & 1 to 3 & 2 \\
\hline 2 & 39.67 & 18.13 & 24.70 & 18.13 & 2.22 & 1 to 3 & 2 \\
\hline 3 & 20.70 & 29.68 & 35.13 & 29.68 & 2.75 & $<1$ & 1 \\
\hline 4 & 40.99 & 14.87 & 42.51 & 14.87 & 1.44 & $<1$ & 1 \\
\hline 5 & 43.21 & 12.16 & 31.25 & 12.16 & 1.31 & 1 to 3 & 2 \\
\hline 6 & 55.74 & 13.53 & 22.42 & 13.53 & 1.46 & 1 to 3 & 2 \\
\hline 7 & 43.63 & 9.97 & 27.59 & 9.97 & 0.90 & 3 to 5 & 3 \\
\hline 8 & 47.56 & 8.35 & 22.79 & 8.35 & 0.76 & $>5$ & 4 \\
\hline 9 & 45.23 & 9.24 & 22.86 & 9.24 & 0.87 & 3 to 5 & 3 \\
\hline 10 & 45.47 & 11.21 & 16.30 & 11.21 & 1.15 & 3 to 5 & 3 \\
\hline 11 & 50.28 & 7.70 & 21.73 & 7.70 & 0.66 & $>5$ & 4 \\
\hline 12 & 50.44 & 8.06 & 22.61 & 8.06 & 0.74 & $>5$ & 4 \\
\hline 13 & 51.67 & 9.91 & 18.66 & 9.91 & 1.13 & 3 to 5 & 3 \\
\hline 14 & 52.27 & 7.52 & 23.07 & 7.52 & 0.70 & $>5$ & 4 \\
\hline 15 & 51.90 & 8.30 & 22.19 & 8.30 & 0.84 & $>5$ & 4 \\
\hline
\end{tabular}

\section{Conclusions}

In the current research, the fuzzy and AHP methods were evaluated for KSP classification of some soils of Fars province, southern Iran. The GIS-based KSP classification needs different parameter maps as inputs, but the relation of these parameters to KSP content is different; therefore, finding the relative weight for each parameter and finally overlaying these maps is really important. In order to overcome these problems, the fuzzy and AHP methods were used in the current study. Results showed that the application of this method is a promising way to determine KSP content. Further development of this method would be worthwhile for application in future studies of KSP. Recently, the fuzzy and AHP methods were successfully used for prediction of soil fertility and land suitability $[19,20,31]$. Considering that soil parameters change constantly based on fuzzy rules, and according to findings of the research, the combination of AHP and fuzzy methods is an accurate tool for the prediction of soil parameters. It is concluded that the combination of AHP and fuzzy methods may be applicable for the prediction of some soil fertility criteria, such as KSP. 
Acknowledgments: The authors would like to acknowledge the Organization of Agriculture, Jihad Fars for their assistance during conducting the present study by providing the required dataset.

Author Contributions: Marzieh Mokarram and Mahdi Najafi-Ghiri carried out and analyzed the data, wrote and revision of the manuscript

Conflicts of Interest: The authors declare no conflict of interest.

\section{References}

1. Najafi-Ghiri, M.; Abtahi, A.; Owliaie, H.; Hashemi, S.S.; Koohkan, H. Factors Affecting Potassium Pools Distribution in Calcareous Soils of Southern Iran. Arid Land Res. Manag. 2011, 25, 313-327. [CrossRef]

2. Sharpley, A.N. Reaction of fertilizer potassium in soils of differing mineralogy. Soil Sci. 1990, 149, 44-51. [CrossRef]

3. Al-Zubaidi, A.; Yanni, S.; Bashour, I. Potassium status in some Lebanese soils. Leban. Sci. J. 2008, 9, 81-97.

4. Pagel, H.; Insa, I. Veranderung wichtiger Grossern des K-Haushaltes in Mangroveboden Guineas unter dem Einfluss der Nutzung. Trans. Int. Congr. Soil Sci. 1974, 4, 349-357.

5. Saaty, T.L. The Analytic Hierarchy Process: Planning, Priority Setting, Resources Allocation; McGraw: New York, NY, USA, 1980.

6. Bello-Dambatta, A.; Farmani, R.; Javadi, A.A.; Evans, B. The Analytical Hierarchy Process for contaminated land management. Adv. Eng. Inform. 2009, 23, 433-441. [CrossRef]

7. Giri, S.; Nejadhashemi, A.P. Application of analytical hierarchy process for effective selection of agricultural best management practices. J. Environ. Manag. 2014, 132, 165-177. [CrossRef] [PubMed]

8. Rahaman, S.A.; Ajeez, S.A.; Aruchamy, S.; Jegankumar, R. Prioritization of Sub Watershed Based on Morphometric Characteristics Using Fuzzy Analytical Hierarchy Process and Geographical Information System-A Study of Kallar Watershed, Tamil Nadu. Aquat. Procedia 2015, 4, 1322-1330. [CrossRef]

9. Ahamed, T.N.; Rao, K.G.; Murthy, J. GIS-based fuzzy membership model for crop-land suitability analysis. Agric. Syst. 2000, 63, 75-95. [CrossRef]

10. Cengiz, T.; Akbulak, C. Application of analytical hierarchy process and geographic information systems in land-use suitability evaluation: A case study of Dümrek village (Çanakkale, Turkey). Int. J. Sustain. Dev. World Ecol. 2009, 16, 286-294. [CrossRef]

11. Rowell, D.L. Soil Science: Methods and Applications; Longman Group Limited, Longman Scientific \& Technical: Essex, UK, 1994.

12. USSL Staff. Diagnosis and Improvement of Saline and Alkali Soils; United States Department of Agriculture: Washington, DC, USA, 1954.

13. Nelson, D.W.; Sommers, L.E.; Sparks, D.; Page, A.; Helmke, P.; Loeppert, R.; Soltanpour, P.; Tabatabai, M.; Johnston, C.; Sumner, M. Total carbon, organic carbon, and organic matter. In Methods of Soil Analysis; Science Society of America: Madison, WI, USA, 1996.

14. Chapman, H.D. Cation-exchange capacity. In Methods of Soil Analysis; Clemson University: Clemson, SC, USA, 1965.

15. Pratt, P.P. Chemical and Microbiological Properties (methodsofsoilanb). In Methods of Soil Analysis; Clemson University: Clemson, SC, USA, 1965; pp. 1022-1030.

16. Goovaerts, P. Geostatistics in soil science: State-of-the-art and perspectives. Geoderma 1999, 89, 1-45. [CrossRef]

17. McBratney, A.B.; Odeh, I.O. Application of fuzzy sets in soil science: Fuzzy logic, fuzzy measurements and fuzzy decisions. Geoderma 1997, 77, 85-113. [CrossRef]

18. Braimoh, A.K.; Vlek, P.L.; Stein, A. Land evaluation for maize based on fuzzy set and interpolation. Environ. Manag. 2004, 33, 226-238.

19. Hamzeh, S.; Mokarram, M.; Alavipanah, S.K. Combination of fuzzy and AHP methods to assess land suitability for barley: Case Study of semi arid lands in the southwest of Iran. Desert 2014, 19, 173-181.

20. Mokarram, M.; Rangzan, K.; Moezzi, A.; Baninemeh, J. Land suitability evaluation for wheat cultivation by fuzzy theory approach as compared with parametric method. ISPRS 2010, 38, 140-145.

21. Burrough, P. Fuzzy mathematical methods for soil survey and land evaluation. J. Soil Sci. 1989, 40, 477-492. [CrossRef] 
22. Najafi Ghiri, M. Study of Morphological and Mineralogical Properties and Potassium Status of Soils of Fars Province. Ph.D. Thesis, Department of Soil Science, Shiraz University, Shiraz, Iran, 2010; p. 222.

23. Nabiollahy, K.; Khormali, F.; Bazargan, K.; Ayoubi, S. Forms of K as a function of clay mineralogy and soil development. Clay Miner. 2006, 41, 739-749. [CrossRef]

24. Al-Zubaidi, A. Potassium status in Iraqi soils. In Proceedings of the Regional Workshop: Potassium and Water Management in West Asia and North Africa; Johnston, A.E., Ed.; International Potash Institute: Horgen, Switzerland, 2003; pp. 129-142.

25. Havlin, J.; Beaton, J.; Tisdale, S.; Nelson, W. Soil Fertility and Fertilizers; Pretince Hall: Upper Saddle River, NJ, USA, 1999.

26. Soil Survey Staff. Soil Taxonomy: A Basic System of Soil Classification for Making and Interpreting Soil Survey; U.S. Government Printing Office: Washington, DC, USA, 1999.

27. Soil Survey Staff. Keys to Soil Taxonomy; Natural Resources Conservation Service: Washington, DC, USA, 2006.

28. Soil Survey Staff. Soil Survey Manual; USDA: Washington, DC, USA, 1993.

29. Ayoubi, Sh.; Jalalian, A. Land Evaluation (Agriculture and Natural Resources); Sanati Isfahan University Press: Isfahan, Iran, 2006.

30. Najafi-Ghiri, M.; Abtahi, A. Factors affecting potassium fixation in calcareous soils of southern Iran. Arch. Agron. Soil Sci. 2012, 58, 335-352. [CrossRef]

31. Bijanzadeh, E.; Mokarram, M. The use of fuzzy-AHP methods to assess fertility classes for wheat and its relationship with soil salinity: East of Shiraz, Iran: A case study. Aust. J. Crop Sci. 2013, 7, 1699-1706.

(C) 2016 by the authors; licensee MDPI, Basel, Switzerland. This article is an open access article distributed under the terms and conditions of the Creative Commons Attribution (CC-BY) license (http:/ / creativecommons.org/licenses/by/4.0/). 